\section{Impoverishing effect of household healthcare expenditure in semi-rural communities in Yenagoa, Nigeria}

\author{
Adedotun Daniel Adesina, \\ Daprim Samuel Ogaji
}

Department of Preventive and Social Medicine, University of Port Harcourt, Nigeria

\begin{abstract}
Inequity in the payment mechanism for healthcare systematically affects poorer households more than the rich. This article examines the impoverishing effect of healthcare expenditure on households in Yenagoa. Data was obtained from a crosssectional survey of households in 2 communities in Yenagoa selected by simple random sampling. A pretested, structured, interviewer-administered questionnaire was used to obtain information on household (HH) income, general expenditures and financing for healthcare. Two international poverty lines designed by World Bank were employed to classify households as poor, extremely poor and to determine the impoverishing effects of households' healthcare expenditures. Responses were received from $525 \mathrm{HHs}$ with $9.2 \%$ of $\mathrm{HHs}$ falling below poverty line, another $9 \%$ pushed deeper into poverty after healthcare spending. A $12.3 \%$ and $16 \%$ increase in the poverty and extreme poverty gaps respectively were attributable to health payment. A significant percentage of households who were non-poor were pushed into poverty after healthcare spending. There is need for increased public spending and implementation of innovative pre-payment mechanisms and social insurance that assures financialrisk protection and equity in health financing in Yenagoa.
\end{abstract}

\section{Introduction}

Inequities in health financing systematically place households (HHs), especially the poor ones, who are already socially disadvantaged at further disadvantage with respect to their health. Hence, health financing options which ensure achievement of the core objectives of 'goodness' and 'fairness' of health systems should be the focus of policy makers and stakeholders in developing equitable distribution of qualitative healthcare goods and services. However, many health systems especially in developing countries are mainly financed privately through out-of-pocket payments for healthcare at the point of access.

The direct out-of-pocket (OOP) payment for health services is an inequitable way to finance a health system as it places great financial burden on households, ${ }^{1}$ excludes financial solidarity ${ }^{2}$ and could compel many households to forgo basic needs such as education, food, and housing in order to pay for healthcare. ${ }^{2-4}$ The usual consequence is that they suffer financial catastrophe or even impoverishment while seeking healthcare. They may also totally avoid or delay to seek necessary healthcare where the cost is perceived to exceed their ability to pay. ${ }^{3-5}$ Nigeria, like many lower middle-income countries (LMIC), relies on OOP payments for financing health services. Fund from private sources is responsible for $75 \%$ of total expenditure on health (THE) and $90 \%$ of this is OOP payments. ${ }^{6,7}$ This payment modality prevent people from seeking or continuing care, while some who do seek care incur catastrophic financial burdens that push them into poverty. ${ }^{8}$ The ensuing vicious cycle of poverty further magnifies the need for healthcare while shrinking the capacity of household to pay for it. ${ }^{9}$ Household spending on health in settings like Nigeria, can also disrupt their budget, making it impossible to meet some essential expenditure in the home. ${ }^{10-16}$

Catastrophic health expenditure which occurs when healthcare expenditures exceed pre-defined proportions of household income and/or non-food expenditure does not completely demonstrate the extent of hardship bore by household after such expenses. ${ }^{11-13,17,18}$ The concept of impoverishment after healthcare spending paints a clearer picture of this financial burden as it demonstrates how expenditure on healthcare could push households into poverty or further down the poverty line. ${ }^{19}$ A study done in Kenya reported that $3.5 \%$ of households and $4 \%$ of households were impoverished by health spending in 2003 and 2007 respectively. Outside the continent of Africa, study done in Brazil also revealed an increasing trend like in Kenya as poverty headcount increased from $6.8 \%$ in $2002 / 2003$ to $11.6 \%$ in $2008 / 2009 .{ }^{15}$ Though a multifaceted social menace, poverty can be measured by the poverty line which defines a monetary threshold below which it becomes difficult for individuals or households to afford basic needs. Poverty lines are commonly defined in relation to average household subsistence spending or 'food share'20 and household per capita income. The World Bank had developed the international poverty lines using per capita
Correspondence: Adedotun Daniel Adesina, Department of Preventive and Social Medicine, University of Port Harcourt, Nigerian Law School, Yenagoa Campus, PMB 60, Yenagoa, Bayelsa State, Nigeria.

Tel.: +234.8034469945

E-mail: adeshinadedotun@yahoo.com

Key words: Out-of-pocket; Impoverishing effect; Poverty line; Healthcare financing; Yenagoa.

Acknowledgements: the authors are grateful to Johnson Igoniderigha and Ipusi Ikiobho staff of Bayelsa Geographic Information System who assisted them in identifying the geographical zones of Yenagoa and assisted in data collection in conjunction with Ibarakumo Sokare and Amani Samuel. They are also grateful to the study communities for agreeing to participate in the study. Finally, they thank Adesina Ileola, Emudiaga-Ohwerhi, Mabel, and Diete-spiff Kaine for their contributions to the project design and overall management of the study.

Contributions: DAA was involved in the conceptualization and design of the study, supervised data collection, data processing and analysis and the initial write up of the manuscript; DSO was involved in the conceptualization and design of the study and the study instrument; he reviewed the data processing and analysis and finally reviewed the manuscript. Both authors approved the final manuscript for publication.

Conflict of interest: the authors declare no potential conflict of interest

Funding: none.

Received for publication: 5 April 2018.

Revision received: 8 July 2018.

Accepted for publication: 30 July 2018 .

This work is licensed under a Creative Commons Attribution 4.0 License (by-nc 4.0).

(C) Copyright A.D. Adesina and D.S. Ogaji, 2018 Licensee PAGEPress, Italy

Healthcare in Low-resource Settings 2018; 6:7464 doi:10.4081/hls.2018.7464

income of households, adjusted for purchasing power parity. The most recent thresholds are US\$1.9 per capita per day and US\$3.1 per capita per day for extreme poverty and poverty respectively. ${ }^{9,11,15} \mathrm{~A}$ non-poor household that becomes poor after paying for healthcare is said to be impoverished by such health expenditures with reference to any of the defined poverty lines. ${ }^{12-}$ 15,20

There is a paucity of studies that quantified the impoverishing effect of health spending on households in this setting. This study aims to bridge this gap by investigat- 
ing the incidence and depth of poverty due to healthcare spending among households in Yenagoa where OOP mechanism of payment is the predominant payment method for healthcare.

\section{Materials and Methods}

\section{Study setting}

The study was conducted in Yenagoa, one of the traditional homes of the Ijaw people and the capital of Bayelsa state. It is located on the banks of Epie and Ekole Creeks, major tributaries of the Nun River between $4^{\circ} 47^{\prime} 15^{\prime \prime}$ and $5^{\circ} 11^{\prime} 55^{\prime \prime}$ North of the equator and Long. $6^{\circ} 07^{\prime} 35^{\prime \prime}$ and $6^{\circ} 24^{\prime}$ $00^{\prime}$ East of the Greenwich meridian. ${ }^{21,22}$

Yenagoa is a semi-rural settlement made up of 21 communities linearly arranged along both sides of the MbiamaYenagoa road $^{22}$ inhabited by people who engage in fishing, farming, palm oil production, palm wine tapping, local gin making, lumbering, craving and weaving. Communities in Yenagoa are organized as compounds with representative family heads. ${ }^{23}$

Yenagoa has at least one primary health care centre in each of its ward and major communities. It is also served by two tertiary health institutions, a number of private hospitals/clinics, patent medicine dealers, and a wide range of non-formal healthcare providers (including traditional medicine practitioners)

\section{Study design}

The study is a cross-sectional survey of households in two randomly selected communities in Yenagoa (Akenfa and Kpansia).

\section{Sampling}

The 2 study communities were selected from the existing 21 communities by simple random sampling. Households were recruitment with the help of the Bayelsa Geographic Information System (BGIS). The three geographical zones of these 2 communities were demarcated and zones 2 and 3 in Kpansia and Akenfa communities respectively were chosen for the study. All roads in the 2 selected zones were identified as clusters from which houses were chosen by systematic random sampling, using the new BGIS numbering system. The interviews were conducted in households selected by simple random sampling (balloting) from the chosen houses.

The number of households needed for this study was calculated using the estimation formula for calculating the required sample size for household survey $\left(\mathrm{n}_{\mathrm{h}}\right)$ which is suitable for international use given by the Department of Economic and Social Affairs, Statistics Division, United Nations: ${ }^{24}$

$$
n_{h}=\left(Z^{2}\right)(r)(1-r)(f)(k) /(p)(n)\left(e^{2}\right) \quad \text { Eq. } 1
$$

where $n_{h}$ is the parameter to be calculated and is the sample size in terms of number of households to be selected;

$\mathrm{z}$ is the statistic that defines the level of confidence desired;

$r$ is an estimate of a key indicator to be measured by the survey;

$\mathrm{f}$ is the sample design effect, Deff, assumed to be 2.0 (default value);

$\mathrm{k}$ is a multiplier to account for the anticipated rate of non-response;

$\mathrm{p}$ is the proportion of the total population accounted for by the target population and upon which the parameter, $r$, is based; $\mathrm{n}$ is the average household size (number of persons per household);

$\mathrm{e}$ is the margin of error to be allowed.

\section{Data collection}

Data was collected by trained data collectors over a period of 5 weeks in July and August 2017 using an extensive questionnaire adapted from previous studies. $7,12,25,26$ The questionnaire investigated household sociodemographic profile, household income, total consumption expenditure, healthcare expenditure and household assets. The study considered:

Household income included all earnings, welfare package or financial benefits accruing to the household from all members of the household not just the income of household head.

Household total consumption expenditure to include spending on health, food and non-food items like rents, transportation, school fees, cable television and mobile phone subscription bills, fuel for generator, clothing, religious contributions and expenses at social events.

Household healthcare expenditure includes expenditures on drug and medicines, consultation fees, hospital bed charges, transport charges to the treatment facilities and daily living cost, including food and lodging for the purpose of caring for the ailing household member. It also included expenditure made on self-medication for minor illnesses and other services sought from alternative/traditional medical practitioners (e.g. TBAs, TBSs and Spiritual healing homes).

The study explicitly explored healthcare payments during episodes of chronic illnesses, hospitalizations, childbirths in the preceding 12-month period (July 2016 -
June 2017) and minor illnesses over 4-week period.

Chronic illness was defined as a condition that is long-lasting (e.g., more than 6 weeks), in many cases lifelong, which needs to be managed on a long-term basis. ${ }^{27}$

Minor illnesses were considered as nonsevere health conditions of less than 6-week duration for which affected household members were treated on outpatient basis.

Hospitalization care were similarly considered as in-patient care received by household members either in the formal health sector or with the alternative/traditional health practitioner. ${ }^{26}$

The study instrument was pre-tested among 30 households in Yenegwe, a small community on the outskirt of Yenagoa. The results obtained were used to improve the different aspects of the questionnaire. The pattern of some of the questions, the arrangement of the sections and the coding of some responses were revised after the pre-test.

\section{Data analysis}

Data generated from the field was directly entered into IBM SPSS 22.0 version which was also used for the analysis. Analyses were done to uncover the demographics, earnings and expenditures of the households. Data was presented as frequency distribution tables and descriptive statistics like means, standard deviation and range were calculated. A principal component analysis was done to group household into different socioeconomic groups.

We estimated household impoverishment by calculating poverty estimates using international poverty and extreme poverty lines of N1,095 (US\$3) and N730 (US\$2) per person per day respectively before and after households made healthcare payments. ${ }^{14}$ The calculated estimates are the poverty headcount, poverty gap and the normalized poverty gap before and after households made health expenditures. These poverty estimates were operationalised as follows:

The poverty headcount represented the percentage of households living below the defined poverty lines. ${ }^{2,5,12,15}$

The poverty gap represented the mean deficit from the poverty line among the study population. It is the average amount by which resources fall short of the defined poverty line. ${ }^{2,5,15}$

The normalized poverty gap was computed by dividing the estimated poverty gap by the defined poverty line. This is useful for international comparisons. . $^{2,5,15}$

All financial estimates were made in Naira which is the Nigerian currency (conversion: US\$1 = 365 Naira). 
The difference between the poverty estimates before and after healthcare expenditure represented the impoverishing effect of health payment. ${ }^{28}$ Thus the differences in poverty headcounts, poverty gaps and normalized poverty gaps before and after health payment represents the impoverishment attributable to health spending.

\section{Ethics and Permission}

Ethical approval was obtained from the University of Port Harcourt research ethics committee. The standard protocol for community entrance was applied and data was obtained from respondents only after the study objectives were explained and a written consent obtained from them.

\section{Results}

\section{Sociodemographic profile of Household}

Responses were received from 525 Households of which majority were headed by males (77\%), had married/cohabiting partners $(70.7 \%)$ and over $90 \%$ of household heads had post-primary education (Table 1).

In total, two thousand five and twentyeight $(2,528)$ persons were studied in the five hundred and twenty-five (525) households with a median household size of 5 . About $17 \%$ of households made health expenditures related to childbirth while others did same when they sought care for long-term health condition (16.2\%) and hospitalization (13\%) (Table 2).

\section{Household income, total consump- tion expenditure and health expen- diture}

Table 3 shows that the household mean monthly income from all sources is N160, 785 with a high level of variability (SD N148, 871). The mean total expenditure on consumption in the study was almost N150, 000 (SD N128, 087) while healthcare gulped on the average N19,520 monthly from the households' income, this corresponds to a mean percentage of $15.9 \%$ of household income spent on health.

\section{Impoverishing effect of healthcare payment}

The mean household income per capita per day was estimated as N1, 220 (SD = 1,073; $\mathrm{SE}=47)$. This estimate reduced to $\mathrm{N} 1,038$ after health spending was discounted from household total income.

The proportion of households (poverty headcount) whose members live on less than the poverty line of N1,095 (US\$3) per day was $58.7 \%$ and $67.9 \%$ before and after discounting household income by household health expenditure respectively, increasing the prevalence of poverty by $9.2 \%$ (Table 4). The results also show that $9 \%$ of poor households were further pushed deeper into extreme poverty by health payment. Other impoverishing impact attributable to health spending are presented in Table 4.

\section{Discussion}

The study demonstrated the impoverishing effect of healthcare expenditure on households in Yenagoa. It showed that a substantial proportion of households are living on the margin of poverty. Almost $10 \%$ of households who were hitherto non-poor were pushed below the poverty line and another $9 \%$ who were poor were further pushed deeper into extreme poverty by healthcare expenditure. A $12.3 \%$ increase in the poverty gap and $16 \%$ increase in the extreme poverty gap were attributable to health payment. The average per capita deficit of N480 suffered by households without healthcare spending increased to approximately N540 after accounting for health spending.

Studies done in India, Kenya and Brazil, reported $3.3 \%, 2.7 \%$ and $2.6 \%$ increase in poverty headcount respectively

Table 1. Sociodemographic of household heads.

\begin{tabular}{|c|c|c|}
\hline Characteristics & Frequency ( $n=525)$ & Percentage (\%) \\
\hline $\begin{array}{l}\text { Sex } \\
\text { Male } \\
\text { Female }\end{array}$ & $\begin{array}{l}404 \\
121\end{array}$ & $\begin{array}{l}77.0 \\
23.0\end{array}$ \\
\hline $\begin{array}{l}\text { Age of household heads (in years) } \\
18-24 \\
25-34 \\
35-44 \\
45-54 \\
55 \text { - } 64 \\
65 \text { and above }\end{array}$ & $\begin{array}{c}9 \\
98 \\
197 \\
120 \\
48 \\
53\end{array}$ & $\begin{array}{c}1.7 \\
18.7 \\
37.5 \\
22.9 \\
9.1 \\
10.1\end{array}$ \\
\hline $\begin{array}{l}\text { Marital status } \\
\text { Single } \\
\text { Married } \\
\text { Divorced/Separated } \\
\text { Widowed }\end{array}$ & $\begin{array}{c}77 \\
371 \\
51 \\
26\end{array}$ & $\begin{array}{c}14.6 \\
70.7 \\
9.7 \\
5.0\end{array}$ \\
\hline $\begin{array}{l}\text { Educational status } \\
\text { No formal education } \\
\text { Primary education } \\
\text { Secondary education } \\
\text { Post-secondary education }\end{array}$ & $\begin{array}{c}9 \\
35 \\
158 \\
323 \\
\end{array}$ & $\begin{array}{c}1.7 \\
6.7 \\
30.1 \\
61.5\end{array}$ \\
\hline $\begin{array}{l}\text { Occupation } \\
\text { Unemployed } \\
\text { Student/Apprentice } \\
\text { Farming/Fishing } \\
\text { Company worker/Artisan } \\
\text { Civil servants } \\
\text { Business owner/ contractor } \\
\text { Professionals } \\
\text { Pensioner }\end{array}$ & $\begin{array}{c}14 \\
18 \\
27 \\
97 \\
181 \\
127 \\
32 \\
29\end{array}$ & $\begin{array}{c}2.7 \\
3.4 \\
5.1 \\
18.5 \\
34.5 \\
24.2 \\
6.1 \\
5.5\end{array}$ \\
\hline $\begin{array}{l}\text { Socioeconomic status }(\mathrm{n}=475) \\
\text { Q1 (Poor) } \\
\text { Q2 (Middle) } \\
\text { Q3 (Wealthy) } \\
\text { Q4 (Wealthiest) }\end{array}$ & $\begin{array}{c}150 \\
273 \\
40 \\
12\end{array}$ & $\begin{array}{c}31.6 \\
57.5 \\
8.4 \\
2.5\end{array}$ \\
\hline $\begin{array}{l}\text { Household Assets (Ownership) } \\
\text { Radio } \\
\text { Television } \\
\text { Fridge } \\
\text { Car } \\
\text { Phone } \\
\text { House } \\
\text { Stocks/Equities }\end{array}$ & $\begin{array}{c}300 \\
508 \\
449 \\
173 \\
519 \\
213 \\
40 \\
\end{array}$ & $\begin{array}{l}57.3 \\
96.9 \\
85.7 \\
33.0 \\
99.0 \\
40.7 \\
7.6\end{array}$ \\
\hline
\end{tabular}


after health expenditures. ${ }^{15,29,30}$ The analysis of household income and expenditure from 11 countries in Asia showed an increase of $3.8 \%$ and $3.6 \%$ in extreme poverty and poverty headcounts respectively after household health spending deductions in Bangladesh which had the most significant proportional variation in the study. ${ }^{4}$ Our finding shows an increase of approximately $9 \%$ in both extreme poverty and poverty headcounts which is higher than these quoted percentages from India, Kenya, Brazil and Bangladesh. However, a direct comparison of the estimates from different studies and countries can be misleading because the different methods that might have been employed in constituting health expenditure and the cutoff to define poverty vary in time and place. Nonetheless, all these studies showed that healthcare spending especially through OOP mechanism have an impoverishing effect on households.

The high proportion of households impoverished in Yenagoa, Bayelsa state due to healthcare spending provides additional support for the recently established Bayelsa health insurance scheme (BHIS). It is expected that stakeholders would galvanize efforts towards the success of this mandato- ry social health insurance scheme in the state. However, there are other important considerations which the operators would need to consider. Notable among these are the provisions for funding premiums for the poor, near poor and other vulnerable groups as contributory mechanisms alone will not ensure universal health coverage in situations where the population is largely poor and/or in the informal sector. ${ }^{14,31}$

It is pertinent to note that from the multi-country study involving 11 Asian countries, Indonesia had the lowest incidence of impoverished households attributable to healthcare payments. ${ }^{4}$ This arose from the country's ability to protect poor

households from high healthcare cost through targeted exemptions with the use of a health card. ${ }^{2}$ Even in developed setting like the UK where hospital services are free at the point of access to all, similar exemptions from co-payment exist for prescribed drugs, dental treatment and eyesight examination for vulnerable population including those with long-term conditions. ${ }^{32}$

Indeed, there are further lessons to learn from the scenario in the $\mathrm{UK}^{32}$ as $16 \%$ and $13 \%$ of households in Yenagoa had at least a member living with at least one long-term condition or hospitalized in the last one year respectively. The enormous financial burden associated with these events can be

Table 2. Morbidity pattern of households.

Characteristics Frequency Percent (\%)

Morbidity pattern in households $(\mathrm{n}=525)$

HHs with members having long term health condition $\quad 85 \quad 16.2$

HHs with members hospitalized

HHs with members that had minor illness

HHs with childbirth

HHs with nonspecific medical conditions

68

265

87

169

13.0

HHs without health expenditure in last 1 year

50.5

16.6

32.2

22.0

Table 3. Household income, total consumption expenditure and healthcare expenditure.

\begin{tabular}{|c|c|c|c|}
\hline Variable & Mean Value (in Naira) & Standard Deviation (in Naira) & Range \\
\hline \multicolumn{4}{|l|}{ HH mean monthly income } \\
\hline Primary income & 150,970 & 140,079 & $(10,000-750,000)$ \\
\hline Collective income (all sources) & 160,785 & 148,871 & $(10,000-1,010,000)$ \\
\hline \multicolumn{4}{|l|}{ HH mean monthly expenditure } \\
\hline Total consumption expenditure & 149,597 & 128,087 & $(12,000-771,925)$ \\
\hline Food expenditure & 60,900 & 32,625 & $(7,000-195,300)$ \\
\hline Non-food expenditure & 73,729 & 80,391 & $(3,450-550,000)$ \\
\hline Total healthcare expenditure & 19,510 & 44,899 & $(0-683,330)$ \\
\hline \multicolumn{4}{|c|}{ Breakdown of HH mean health care expenditure } \\
\hline Long-term medical condition & 4,515 & 15,475 & $(0-200,000)$ \\
\hline Minor illness & 8,940 & 3,709 & $(0-35,000)$ \\
\hline Childbirth & 3,150 & 6,980 & $(0-46,000)$ \\
\hline Hospitalization & 6,770 & 28,630 & $(0-333,330)$ \\
\hline Non-specific health payments & 3,065 & 7,278 & $(0-86,000)$ \\
\hline
\end{tabular}

Table 4. Impoverishment estimates before and after health expenditure.

\begin{tabular}{|c|c|c|c|c|}
\hline & $\begin{array}{l}\text { Before discounting } \\
\text { health payment (1) }\end{array}$ & $\begin{array}{l}\text { After discounting } \\
\text { health payment ( } 2 \text { ) }\end{array}$ & $\begin{array}{c}\text { Difference (Absolute) } \\
(3)=(2)-(1)\end{array}$ & $\begin{array}{c}\text { Difference } \\
\text { (Relative) }[(3) /(1) * 100\end{array}$ \\
\hline \multicolumn{5}{|c|}{ Assessment using the $\$ 3.00$ (1,095 Naira) capita/day poverty line } \\
\hline Poverty Headcount (\%) & 58.7 & 67.9 & 9.2 & 15.7 \\
\hline Poverty gap (Naira) & 482.4 & 541.6 & 59.2 & 12.3 \\
\hline Normalized Poverty Gap (\%) & 44.1 & 49.5 & 5.4 & 12.2 \\
\hline \multicolumn{5}{|c|}{ Assessment using the $\$ 2.00$ (730 Naira) capita/day extreme poverty line } \\
\hline Poverty Headcount (\%) & 37.8 & 46.8 & 9.0 & 23.8 \\
\hline Poverty Gap (Naira) & 280.2 & 324.9 & 44.7 & 16.0 \\
\hline Normalized Poverty Gap (\%) & 38.4 & 44.5 & 6.1 & 15.9 \\
\hline
\end{tabular}


ameliorated with expanded funding options for public health services that can guarantee improved access to hospital care for all and exemption of poorer households from all co-payments as part of a broader social security system.

Although the relative increase of $15.7 \%$ and $12.3 \%$ in the headcount and depth of poverty respectively are worrisome, this may still represent an underestimation of the impoverishing effect of healthcare cost on households in Yenagoa as indirect costs and lost earnings by households with sick members were not accounted for in this study. Like the Kenyan study, ${ }^{18}$ underestimation could also arise from the $22 \%$ of households that reported zero spending on healthcare in the one-year recall period. The zero spending may reflect non-recall or denial of past illness episodes which are often given negative connotations or because they had completely forgone care due to lack of resources, not necessarily because they do not need healthcare.

Interestingly, while impoverishment as a result of health expenditures occurs in all countries irrespective of income levels, its prevalence is higher in countries which depend predominantly on OOP payment mechanisms like Nigeria. ${ }^{6,33,34}$ A quick recommendation would be urging all leaders in Africa to increase public spending on health to at least achieve the target of $15 \%$ endorsed at the Abuja declaration. ${ }^{35}$ This would appear difficult in view of other formidable challenges, dwindling public revenue and lack of political will in these countries. However, widening the sources of funding may just well be the way out. In this regard, a range of innovative prepayment methods including the National Health Insurance Scheme (NHIS) should be introduced, strengthened and expanded to achieve national coverage.

Although this community-based study quantified and deduced the impoverishing effect of healthcare expenditure, its limitations arise from the fact that only the total OOP expenditures was reported without categorizing them into healthcare expenditure subheads like fees for drug, consultation, investigation, transportation, accommodation as was done in similar studies. ${ }^{33-34}$ This categorization would have helped identified the specific spending that influenced household impoverishment the most in our setting.

Furthermore, applying a longitudinal approach is more apt and reliable in studying expenditures and their impact on household impoverishment. The paucity of longitudinal data on the subject may not be unrelated to the difficulties in implementing such research protocols, hence researchers often resort to cross sectional designs. $2,11,13,15,18,33-34,36,37$ Despite these limitations, findings from this study would be a useful guide in the on-going implementation of the state-wide health financing model that would minimize systematic disparities while ensuring the achievement of universal health coverage for the population.

\section{Conclusions}

A significant percentage of households who are marginally non-poor were pushed into poverty because of healthcare expenditure. There is need for increased public spending on healthcare, implementation of innovative and progressive pre-payment mechanisms as well as exemption from payment by vulnerable households that would assure financial risk protection, guarantee equity in health financing and universal coverage for households in Yenagoa, Bayelsa state.

\section{References}

1. World Health Organization. The world health report 2000: health systems: improving performance. World Health Organization; 2000.

2. Kimani DN, Mugo MG, Kioko UM. Catastrophic health expenditures and impoverishment in Kenya. ESJ. 2016;12:434-52.

3. Baeza C, Packard T. Beyond survival: protecting households from health shocks in Latin America. Stanford University Press; 2006.

4. Van Doorslaer E, O'Donnell O, RannanEliya RP, et al. Effect of payments for health care on poverty estimates in 11 countries in Asia: an analysis of household survey data. Lancet 2006;368:1357-64.

5. Wagstaff A, Doorslaer EV. Catastrophe and impoverishment in paying for health care: with applications to Vietnam 1993-1998. Health Econ 2003;12:921-33.

6. World Health Organization. World health statistics 2015. World Health Organization; 2015.

7. Onwujekwe OE, Uzochukwu BS, Obikeze EN, et al. Investigating determinants of out-of-pocket spending and strategies for coping with payments for healthcare in southeast Nigeria. BMC Health Serv Res 2010;10:67.

8. Xu K, Evans DB, Carrin G, et al. Protecting households from catastrophic health spending. Health Affairs
2007;26:972-83.

9. World Bank Group. World Development Report-A Better Investment Climate for Everyone; 2005. Available from: siteresources.worldbank.org/INTWDR 2005/Resources/complete_report.pdf

10. Su TT, Kouyaté B, Flessa S. Catastrophic household expenditure for health care in a low-income society: a study from Nouna District, Burkina Faso. Bull World Health Org 2006;84:21-7.

11. Rashad AS, Sharaf MF. Catastrophic economic consequences of healthcare payments: Effects on poverty estimates in Egypt, Jordan, and Palestine. Economies 2015;3:216-34.

12. Xu K, Evans DB, Kawabata K, et al. Household catastrophic health expenditure: a multicountry analysis. Lancet 2003;362:111-7.

13. Mchenga M, Chirwa GC, Chiwaula LS. Impoverishing effects of catastrophic health expenditures in Malawi. Int J Equity Health 2017;16:25.

14. Hoang VM, Oh J, Tran TA, et al. Patterns of health expenditures and financial protections in Vietnam 19922012. J Korean Med Sci 2015;30:S1348.

15. Boing AC, Bertoldi AD, Posenato LG, Peres KG. The influence of health expenditures on household impoverishment in Brazil. Rev Saude Publ 2014;48:797-807.

16. Elgazzar H, Raad F, Arfa C, et al. Who pays? Out-of-pocket health spending and equity implications in the Middle East and North Africa. 2010 Health, Nutrition and Population (HNP) Discussion Paper. Washington DC: The World Bank; 2010.

17. Kusi A, Hansen KS, Asante FA, Enemark U. Does the National Health Insurance Scheme provide financial protection to households in Ghana? BMC Health Serv Res 2015;15:331.

18. Buigut S, Ettarh R, Amendah DD. Catastrophic health expenditure and its determinants in Kenya slum communities. Int J Equity Health 2015;14:46.

19. Wagstaff A. Measuring financial protection in health. World Bank, Washington, DC; development research group. Policy research working paper\# WPS 2008;4554.

20. Xu K, World Health Organization. Distribution of health payments and catastrophic expenditures methodology. Discussion paper No. 2. HSF, World Health Organization; 2005.

21. Koinyan AA, Nwankwoala HO, Eludoyin OS. Water resources utiliza- 
tion in Yenagoa, Central Niger Delta: Environmental and health implications. Int $\mathrm{J}$ Water Res Environ Engin 2013;5:177-86.

22. Iyorakpo J. Impact of Rapid Urbanization on Environmental Quality in Yenagoa Metropolis, Bayelsa StateNigeria. ESJ 2015;11:255-68.

23. National Population Commission Abuja, Nigeria. 2006 Housing population Census: Population on distribution by age and sex: State and Local Government Area, Priority Table. National Population Commission 2010;4:54-8.

24. Department of Economic and Social Affairs, Statistics Division, United Nations. Designing Household Survey Samples: Practical Guidelines. Studies in Methods Series F No.98 New York, 2005. pp 44-46.

25. Musoke D, Boynton P, Butler C, Musoke MB. Health seeking behaviour and challenges in utilising health facilities in Wakiso district, Uganda. Afr Health Sci 2014;14:1046-55.

26. Mondal S, Kanjilal B, Peters DH, Lucas H. Catastrophic out-of-pocket payment for health care and its impact on house- holds: Experience from West Bengal, India. Future Health Syst Innov Equity 2010. Available from: http://www.chronicpoverty.org/uploads /publication_files/mondal_et_al_health. pdf

27. Choi JW, Choi JW, Kim JH, et al. Association between chronic disease and catastrophic health expenditure in Korea. BMC Health Serv Res 2015; 15:26.

28. Berki SE. A look at catastrophic medical expenses and the poor. Health Affairs 1986;5:138-45.

29. Garg CC, Karan AK. Reducing out-ofpocket expenditures to reduce poverty: a disaggregated analysis at rural-urban and state level in India. Health Policy Plann 2008;24:116-28.

30. Chuma J, Maina T. Catastrophic health care spending and impoverishment in Kenya. BMC Health Serv Res 2012;12:413.

31. Somanathan A, Tandon A, Dao HL, et al. Moving toward universal coverage of social health insurance in Vietnam: assessment and options. World Bank; 2014.

32. World Health Organization. World
Health Report, 2010: health systems financing the path to universal coverage. World Health Organization; 2010.

33. Ogaji DS, Nwi-ue LB, Agalah HN, et al. Impact and contributors to cost of managing long term conditions in a university hospital in Nigeria. J Commun Med Primary Health Care 2015;27:3040.

34. Ogaji DS, Mark OC, Oghenetega EP, et al. Cost burden for Accessing Paediatric Emergency Services at a Tertiary Health Facility. Niger Health J 2015;15:10310.

35. Birch S. Health care charges: lessons from the UK. Health Policy 1989;13:145-57.

36. Barasa EW, Maina T, Ravishankar N. Assessing the impoverishing effects, and factors associated with the incidence of catastrophic health care payments in Kenya. Int J Equity Health 2017;16:31.

37. Levie A, Xu K. Coping with out-ofpocket health payments: empirical evidence from 15 African countries. Bull World Health Org 2008;86:849-56C. 